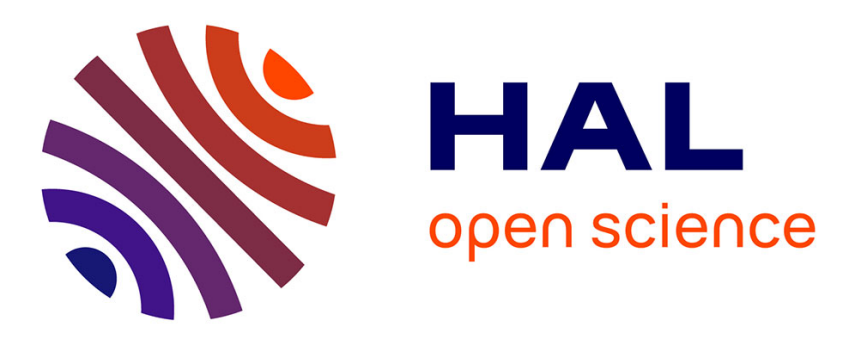

\title{
Recent Advances in the Synthesis of Benzimidazole Derivatives from the Oxidative Coupling of Primary Amines
}

\author{
Martine Largeron, Khac Minh Huy Nguyen
}

\section{- To cite this version:}

Martine Largeron, Khac Minh Huy Nguyen. Recent Advances in the Synthesis of Benzimidazole Derivatives from the Oxidative Coupling of Primary Amines. Synthesis: Journal of Synthetic Organic Chemistry, 2018, 50 (02), pp.241-253. 10.1055/s-0036-1590915 . hal-02384557

\section{HAL Id: hal-02384557 \\ https://hal.science/hal-02384557}

Submitted on 26 Nov 2020

HAL is a multi-disciplinary open access archive for the deposit and dissemination of scientific research documents, whether they are published or not. The documents may come from teaching and research institutions in France or abroad, or from public or private research centers.
L'archive ouverte pluridisciplinaire HAL, est destinée au dépôt et à la diffusion de documents scientifiques de niveau recherche, publiés ou non, émanant des établissements d'enseignement et de recherche français ou étrangers, des laboratoires publics ou privés. 


\section{Recent Advances in the Synthesis of Benzimidazole Derivatives from the Oxidative Coupling of Primary Amines}

\author{
M. Largeron*a \\ K. M. H. Nguyen ${ }^{a, 1}$
}

a UMR 8638 CNRS-Université Paris Descartes (Paris 5),

Sorbonne Paris Cité, Faculté de Pharmacie de Paris, 4 avenue de l'Observatoire, 75270 Paris cedex 06 (France)

martine.largeron@parisdescartes.fr

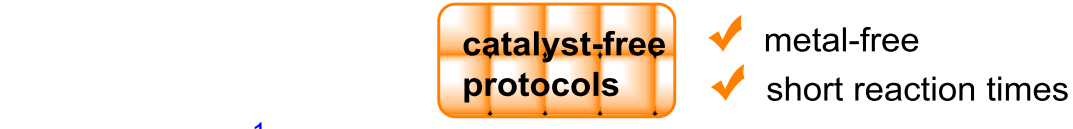<smiles>[R]CNCc1ccc([R9])cc1N[R7]</smiles>

oxidative cross-coupling<smiles>[R3]c1ccc2nc([R])n([R])c2c1</smiles>

$\checkmark \mathrm{Cu}$, Fe metals

$\checkmark$ photocatalyst

\section{catalyzed \\ methods}

organocatalyst bioinspired catalyst
Abstract Benzimidazole belongs to the top five most commonly used fivemembered aromatic nitrogen heterocycles among U.S. FDA approved pharmaceuticals. Over the last few years, a large number of improved synthetic strategies have been developed to construct the benzimidazole molecular framework under environmentally benign conditions. This review focuses on the use of primary amines as readily available substrates for the synthesis of benzimidazole derivatives through different types of oxidative cross-coupling reactions.

1. Introduction

2. Catalyst-free oxidative coupling of primary amines

3. Catalytic oxidative coupling of primary amines

3.1 Metal-catalyzed reactions

3.2 Metal-free catalyzed reactions

3.3 Bioinspired catalyzed reactions

4. Conclusion

Key words oxidation, homogeneous catalysis, heterogeneous catalysis, cross-coupling, amine, imine, benzimidazole

\section{Introduction}

Nitrogen heterocycles are among the most privileged and significant structural components of pharmaceuticals. ${ }^{2}$ A recent analysis of the nitrogen heterocyclic composition of U.S. FDA (Food and Drug Administration) approved drugs has revealed the relative frequency by which the various nitrogen heterocycles have been incorporated into approved drugs architecture. ${ }^{3}$ Interestingly, benzimidazole was found to be the fifth most commonly used five-membered aromatic nitrogen heterocycles after thiazole, imidazole, indole and tetrazole. Benzimidazoles are found in thirteen U.S. FDA approved drugs exhibiting diverse pharmaceutical properties. Five of these drugs are structurally similar proton pump inhibitors including the well known omeprazole, also marketed as the single enantiomer sulfoxide variant esomeprazole (Figure 1).

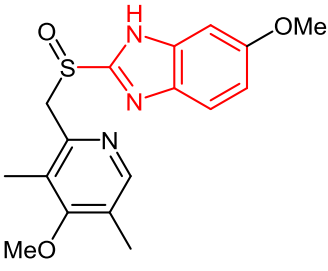

Omeprazole Esomeprazole (S)<smiles>CCOc1nc2cccc(C(=O)O)c2n1Cc1ccc(-c2ccccc2-c2nnn[nH]2)cc1</smiles>

Candesartan<smiles>COc1ccc(CCN2CCC(Nc3nc4ccccc4n3Cc3ccc(F)cc3)CC2)cc1</smiles>

Astemizole<smiles>Cn1c(CCCC(=O)O)nc2cc(C(CCCl)CCCl)ccc21</smiles>

Bendamustine
Figure 1 Representative pharmaceuticals containing a benzimidazole scaffold

Five of the benzimidazole drugs, candesartan, telmisartan, azilsartan, medoxomil and mibefradil, are used as antihypertensives whereas astemizole and emedastine are antihistaminic agents. Lastly, bendamustine acts as an alkylating agent for the treatment of chronic lymphocytic leukemia and dabogatran elexilate mesylate is used to prevent the risk of stroke. Interestingly, almost all drugs are 1,2-disubstituted benzimidazole derivatives.

Owing to the prevalence of the benzimidazole molecular framework, tremendous efforts have been devoted to the 
synthesis of functionalized benzimidazole derivatives, which are traditionally prepared from $o$-aminoanilines by condensation with carboxylic acid derivatives under harsh dehydrating conditions or by oxidative coupling with aldehydes. ${ }^{4}$ Although the oxidative condensation of $o$-aminoanilines with aldehydes remains the most popular way to prepare these targets, this strategy suffers some drawbacks such as air-sensitive catalysts, stoichiometric or excess amount of oxidants, low yields, high reaction temperature and the competitive formation of 2 substituted and 1,2-disubstituted benzimidazoles. ${ }^{5}$ Recent advances have been dominated by the development of improved procedures in terms of operational simplicity, atom economy and ecofriendly viability, which selectively lead to either 2substituted benzimidazoles ${ }^{6}$ or 1,2-disubstituted benzimidazoles as the sole product. ${ }^{7}$

The regiodefined 1,2-disubstitution on the benzimidazole scaffold being a structural characteristic of pharmaceuticals, numerous alternative strategies have been developed for the regiocontrolled synthesis of 1,2-disubstituted benzimidazoles. ${ }^{8}$ In particular, catalytic amination of 2-haloacetatanilides and catalyzed intramolecular C-N cross-coupling reactions starting from amidines have widely been utilized. ${ }^{9}$ However, these routes require special efforts to prepare the desired starting materials, thus limiting the potential applications of these methods.

Recently, oxidative cross-coupling reactions employing alcohols and $o$-aminoanilines as substrates have received great attention for selectively producing 2-substituted benzimidazoles without the concomitant formation of 1,2disubtituted benzimidazoles. ${ }^{10}$ However, with few exceptions, $10 \mathrm{~d}$,h, high reaction temperature $\left(90-160{ }^{\circ} \mathrm{C}\right)$, oxygen pressure or expensive transition-metal catalysts are still required.

This review focuses on the utilization of primary amines as readily available substrates in the oxidative cyclocondensation reaction with $o$-aminoanilines to construct the benzimidazole framework (Scheme 1). The attractive features of this protocol include the use of commercially available amines, high atom economy and high selectivity towards the products. Furthermore, a large molecular diversity could be attained through the variation of both aliphatic amines and $o$ aminoanilines.

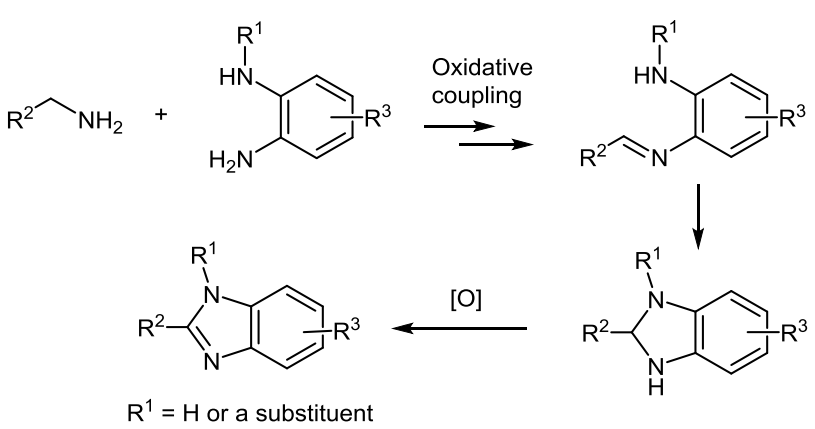

Scheme 1 Oxidative cyclocondensation of primary amines with o-aminoanilines leading to benzimidazole derivatives

Different types of oxidative cross-coupling with $o$ aminoanilines are presented, covering literature mainly published during the last five years. Catalyzed methods are organized into three sections, for metal-catalyzed, metal-free and bioinspired reaction types.

\section{Catalyst-free oxidative coupling of primary amines}

Sustainable development has been accepted as a common knowledge in current society. In response to this challenge, the development of green processes, which reduce chemical waste and handling costs, is highly desirable.

Accordingly, Nguyen and co-workers have reported simple solvent-free and catalyst-free procedures for the synthesis of substituted benzimidazoles. Especially, they have performed oxidation reactions of various aliphatic amines using elemental sulfur as a readily available, nontoxic and stable oxidant, in the presence of $o$-aminoanilines, which are not sensitive to sulfurmediated oxidation. ${ }^{11}$ By heating an equimolar mixture of aliphatic amine and $o$-aminoaniline, at $150^{\circ} \mathrm{C}$, in the presence of an excess of elemental sulfur ( 3 equiv), under solvent-free conditions, 2-substituted benzimidazoles could be isolated in high yields. Using a slight excess of $o$-aminoaniline ( 1.5 equiv), the reaction temperature could be decreased to $130{ }^{\circ} \mathrm{C}$ and the isolated yield could reach $92 \%$ (Figure 2). Interestingly, aliphatic amines other than benzylic amines can be oxidized by elemental sulfur allowing introduction of alkyl substituents at the 2-position of the benzimidazole core.

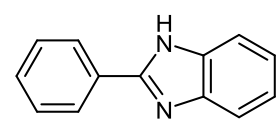

$92 \%$

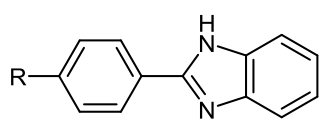

$\mathrm{R}=\mathrm{Me}, 90 \% ; \mathrm{R}=\mathrm{Cl}, 86 \%$ $\mathrm{R}=\mathrm{OMe}, 85 \%$<smiles>c1ccc(Cc2nc3ccccc3[nH]2)cc1</smiles>

$90 \%$<smiles>Cc1nc2ccccc2[nH]1</smiles>

$90 \%$<smiles>CCc1nc2ccccc2[nH]1</smiles>

$85 \%$<smiles>Cc1ccc2nc(-c3ccccc3)[nH]c2c1</smiles>

$82 \%$

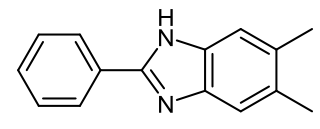

$78 \%$<smiles>c1ccc2[nH]c(-c3ccncc3)nc2c1</smiles>

$73 \%$<smiles>Clc1ccc2nc(-c3ccncc3)[nH]c2c1</smiles>

$81 \%$<smiles>c1ccc(-c2nc3ccccc3[nH]2)nc1</smiles>

$85 \%$

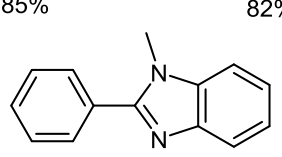

$85 \%$
Figure 2 Yields of representative benzimidazole derivatives prepared from sulfur-mediated cross-coupling of amines ${ }^{11}$

The reaction mechanism involved the intermediary formation of a homocoupled thioamide (Scheme 2), as the result of the oxidation of aliphatic amine by elemental sulfur, followed by trans-thioamidation which was energetically facilitated by 
subsequent cyclization and aromatization steps (Scheme 1). So sulfur was not incorporated in the final product but was used as a traceless oxidizing reagent. Interestingly, this protocol was also effective for the preparation of benzothiazoles and benzoxazoles, the thia- and oxa-analogues of benzimidazoles.

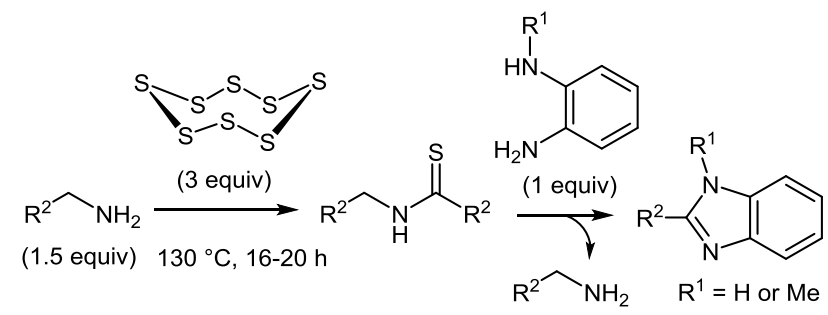

Scheme 2 Sulfur-mediated oxidative coupling of aliphatic amines with $o$-aminoanilines affording benzimidazoles

Nguyen and co-workers have also described a solvent-free autoxidation system for the synthesis of 2-substituted benzimidazoles by simply heating a mixture of benzylic primary amines and $o$-aminoanilines, at $110{ }^{\circ} \mathrm{C}$, under $1 \mathrm{~atm}$ of $\mathrm{O}_{2}$ for 24 $\mathrm{h}$, in the presence of acetic acid (20 mol\%) as a cyclizing promoter. $^{12}$ Although this catalyst-free and solvent-free methodology was attractive from the viewpoint of sustainable chemistry, the substrate scope was limited to benzylic-type substrates. However, this solvent-free autoxidation system could also be applied to the synthesis of 2,3-dihydroquinazolin4-(1H)-one and quinazolin-4- $(3 H)$-one derivatives, in acceptable yields ranging from 60 to $72 \%$, by changing $o$-aminoaniline to anthranilamide as the coupling partner, while increasing the amount of acetic acid to $40 \mathrm{~mol} \%$ and the temperature to 120 $150{ }^{\circ} \mathrm{C}$ (Scheme 3). Note the quinazoline framework is also part of the top 25 most commonly utilized nitrogen heterocycles found in pharmaceuticals. ${ }^{3}$

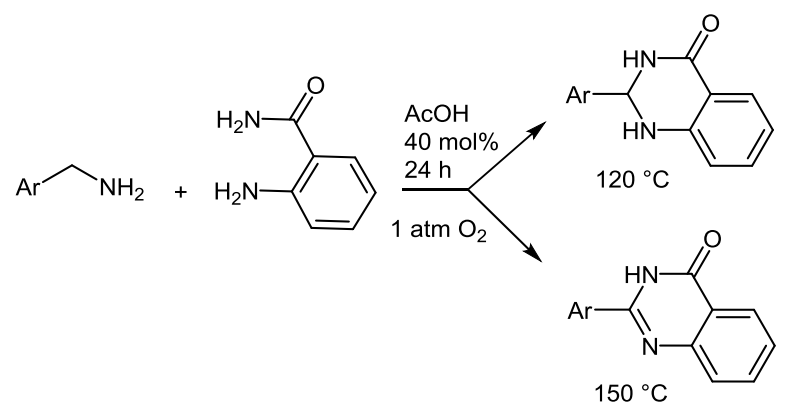

Scheme 3 Solvent-free autoxidation of benzylic amines allowing the synthesis of quinazoline derivatives

$\mathrm{Yu}$ and Lu have reported a similar catalyst-free and solventfree oxidative synthesis of 2-substituted benzimidazole derivatives. ${ }^{13}$ Using an excess of tert-butyl hydroperoxide (TBHP, 4 equiv, 70\% in $\mathrm{H}_{2} \mathrm{O}$ ) as the oxidant instead of $1 \mathrm{~atm}$ $\mathrm{O}_{2},{ }^{12}$ a significant reduction of the reaction time $(5-12 \mathrm{~h}$ against $24 \mathrm{~h}$ ) was observed. Following the reaction scheme 1, various 2substituted benzimidazoles were synthesized at $100{ }^{\circ} \mathrm{C}$ starting from 1 equiv of benzylic or allylic primary amines and 1.5 equiv of $o$-aminoanilines (Figure 3).

Recently, Kamal and co-workers have developed a metal-free one-pot protocol for the synthesis of 2-substituted benzimidazole derivatives which proceeds through the oxidation of benzylic amines by an inexpensive mild oxidant phenyliodonium diacetate (PIDA). ${ }^{14}$

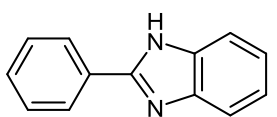

$82 \%$

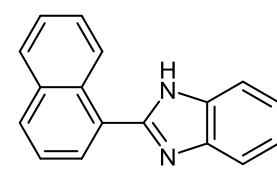

$83 \%$

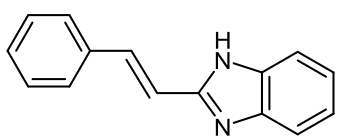

$42 \%$

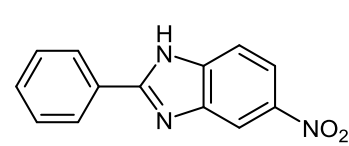

$73 \%$

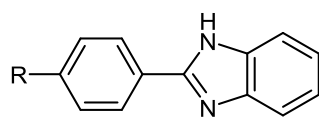

$\mathrm{R}=\mathrm{Br}, 85 \% ; \mathrm{R}=\mathrm{Cl}, 84 \%$

$\mathrm{R}=\mathrm{NO}_{2}, 86 \% ; \mathrm{R}=\mathrm{OMe}, 77 \%$

$\mathrm{R}=\mathrm{NMe}_{2}, 76 \%$

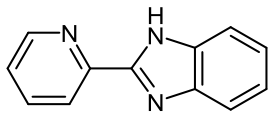

$68 \%$<smiles>c1coc(-c2nc3ccccc3[nH]2)c1</smiles>

$65 \%$

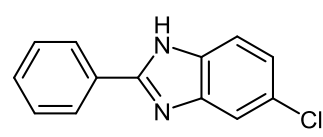

$84 \%$
Figure 3 Yields of representative 2-substituted benzimidazoles synthesized through TBHP-mediated oxidative cross-coupling ${ }^{13}$

By heating 1.2 equiv of both PIDA and benzylic amine together with 1 equiv of $o$-aminoaniline, at $80{ }^{\circ} \mathrm{C}$ for $4 \mathrm{~h}$, in a mixture of DMSO and $\mathrm{H}_{2} \mathrm{O}$ (1:1 ratio) as the solvent, 2-substituted benzimidazoles could be isolated in high yields ranging from 77 to $92 \%$. The reaction mechanism involved the oxidative addition of PIDA with benzylamine substrate, followed by the formation of a benzaldimine intermediate which rapidly hydrolyzed to give the corresponding benzaldehyde (Scheme 4). Further oxidative cyclocondensation with $o$-aminoanilines led to the corresponding 2-substituted benzimidazole product. Interestingly, the methodology could be extended to the synthesis of biologically relevant quinazolinone derivatives, when anthranilamide was used instead of $o$-aminoanilines by heating the reaction mixture at $100{ }^{\circ} \mathrm{C}$ for $6 \mathrm{~h}$.

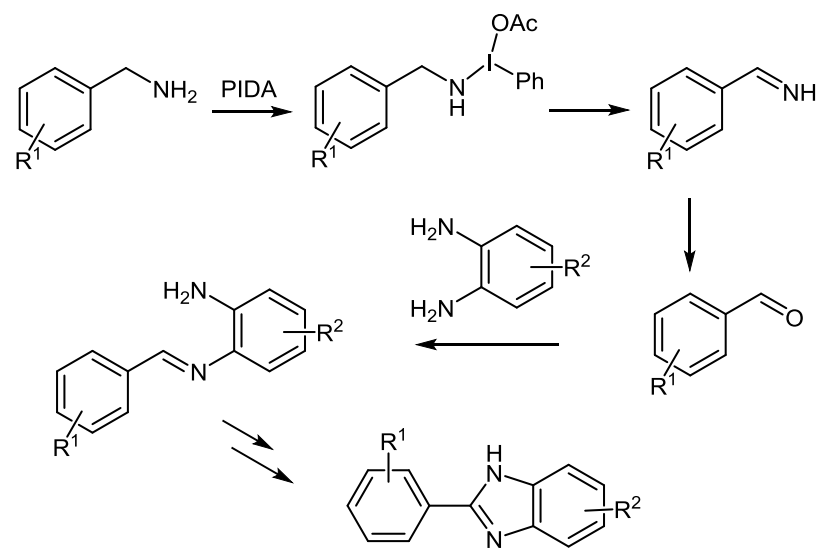

Scheme 4 Proposed reaction mechanism for the PIDApromoted synthesis of 2 -substituted benzimidazole derivatives 
A last example of catalyst-free oxidative coupling of primary amines merits special note because of the exceptionally mild reaction conditions utilized. Narender and co-workers have developed a simple method for the iodine-mediated synthesis of 2-substituted benzimidazole derivatives which allows the C-N bond formation at room temperature. ${ }^{15}$ The oxidative crosscoupling of benzylic amine (1.5 equiv) with $o$-aminoaniline $(1$ equiv) was promoted by 2 equiv of iodine in acetonitrile, leading to the desired benzimidazole product in only $30 \mathrm{~min}$. The initial step of the reaction mechanism involves the oxidation of the benzylic amine by iodine to give, after elimination of ammonia, an homocoupled imine intermediate which could be isolated (Scheme 5). After dynamic transimination, the generated crosscoupled imine underwent intramolecular cyclization and subsequent oxidation as shown in reaction scheme 1 affording 2-substituted benzimidazoles in good yields ranging from 58 to $82 \%$. However, aliphatic primary amines other than benzylic amines failed to provide 2-substituted benzimidazoles under the same experimental conditions.

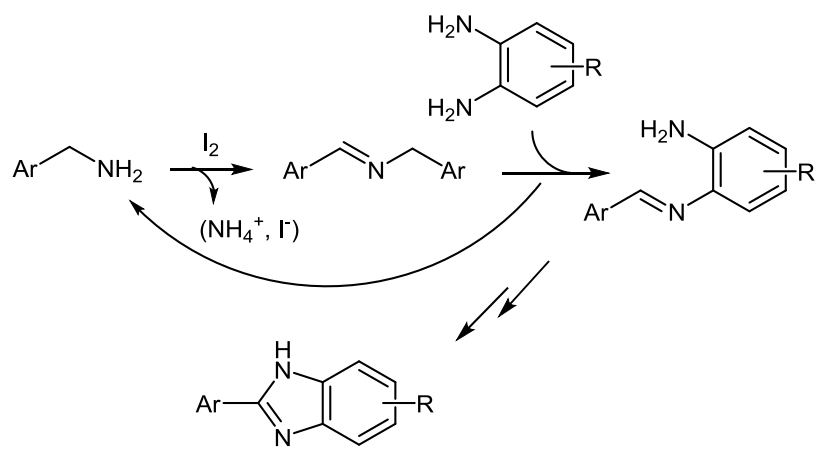

Scheme 5 Proposed reaction mechanism for the $\mathrm{I}_{2}$-mediated synthesis of 2-substituted benzimidazole derivatives

Replacing $o$-aminoaniline by mercaptoaniline, 2-substituted benzothiazoles could be prepared under similar reaction conditions. Furthermore, a new class of 2-benzyl-3-phenyl-3,4dihydro- $2 H$-benzo $[e][1,2,4]$ thiadiazines was discovered in ethyl acetate, which involved both metal-free $\mathrm{C}-\mathrm{N}$ and S-N bond formation, illustrating the efficiency of the process (Scheme 6).

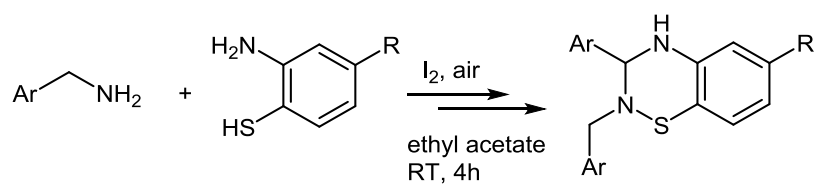

Scheme $6 \mathrm{I}_{2}$-mediated formation of 2-benzyl-3-phenyl-3,4dihydro- $2 H$-benzo $[e][1,2,4]$ thiadiazines

During the last five years, new and more environmentally friendly strategies for the catalyst-free oxidative coupling of primary amines to construct the benzimidazole framework have been identified.11-15 At the same time, significant progress has resulted from the discovery of selective catalytic systems that avoid using stoichiometric or excess amounts of specific oxidants, which adversely affect the economics as well as the ecofriendly nature of the reaction.

\section{Catalytic oxidative coupling of primary amines}

The development of processes that satisfy environmental constraints is in current demand from the pharmaceutical and chemical industries. In this respect, the use of low loadings of catalysts, with molecular oxygen atmosphere or, much better, ambient air as the sole oxidant, is particularly attractive from the viewpoint of green chemistry.

\subsection{Metal-catalyzed reactions}

For years, the major weakness of metal-catalyzed reactions has been the use of expensive precious- and rare-metal catalysts, which did not meet the requirements of sustainable and green chemistry. Recently, earth abundant or biocompatible metals, especially copper and iron, have attracted much attention due to their low cost and low toxicity. ${ }^{16}$

Although the aerobic copper-catalyzed oxidation of primary amines to imines was previously described, ${ }^{17}$ Zhou and coworkers were the first to report a Cu-catalyzed aerobic oxidative cyclocondensation of benzylic amines with $o$ aminoanilines for the synthesis of 2-substituted benzimidazole derivatives. ${ }^{18}$ The reactions were carried out in toluene, at 100 ${ }^{\circ} \mathrm{C}$ under air for $24 \mathrm{~h}$, using benzylic amines (1.2 equiv) and $o$ aminoanilines ( 1 equiv), in the presence of low loading of $\mathrm{CuBr}_{2}$ ( $1 \mathrm{~mol} \%$ ) as the catalyst. In the presence of $o$-aminoaniline, variously substituted benzylamines afforded the corresponding 2-substituted benzimidazoles in 79-92\% yields regardless of the electronic character of the substituents (Figure 4). Likewise, the reaction was not significantly affected by the substituents on the aromatic ring of $o$-aminoaniline, when benzylamine was used as the amine substrate, producing the corresponding 2-substituted benzimidazole derivatives in high yields (80-93\%). Furthermore, the methodology could be extended to the synthesis of their structural isosteres, benzothiazole and benzoxazole.

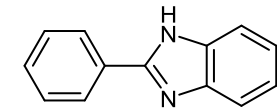

$91 \%$

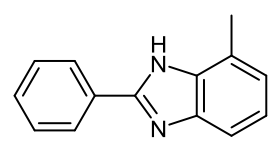

$87 \%$

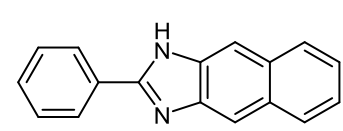

$80 \%$

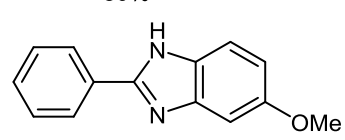

$83 \%$

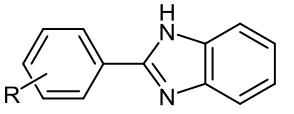

$\mathrm{R}=p-\mathrm{Br}, 83 \% ; \mathrm{R}=p-\mathrm{Cl}, 84 \%$ $\mathrm{R}=p-\mathrm{F}, 92 \% ; \mathrm{R}=p-\mathrm{OMe}, 94 \%$ $\mathrm{R}=p-\mathrm{Me}, 88 \% ; \mathrm{R}=o-\mathrm{Me}, 89 \%$; $\mathrm{R}=m-\mathrm{Me}, 87 \%$<smiles>c1csc(-c2nc3ccccc3[nH]2)c1</smiles><smiles>c1coc(-c2nc3ccccc3[nH]2)c1</smiles>

$85 \%$ $79 \%$<smiles>c1ccc(-c2nc3ccccc3[nH]2)nc1</smiles>

$82 \%$

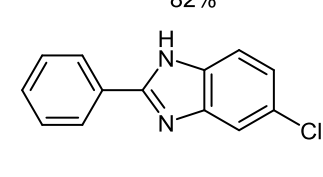

$93 \%$
Figure 4 Yields of representative 2-substituted benzimidazoles synthesized through $\mathrm{CuBr}_{2}$-mediated oxidative cross-coupling ${ }^{18}$ 
$\mathrm{Xu}$ and co-workers have reported a similar action of $\mathrm{CuI}(5$ mol\%) for the catalyzed oxidative cyclocondensation of benzylic amines ( 2 equiv) and $o$-aminoanilines ( 1 equiv) in toluene, at $100{ }^{\circ} \mathrm{C}$ under air for $48 \mathrm{~h} .{ }^{19}$ The yields of isolated 2-substituted benzimidazole derivatives were acceptable, ranging from 41 to $83 \%$. Noteworthy, variously substituted benzothiazoles and benzoxazoles could also be prepared through this protocol. Obviously, CuI was less effective than $\mathrm{CuBr}_{2}$ to promote this kind of transformation. ${ }^{18}$ Nevertheless, at a slightly more elevated temperature of $130{ }^{\circ} \mathrm{C}$ for $24 \mathrm{~h}$, CuI was also able to catalyze the oxidation of 2-phenylethylamine, which, in the presence of $o$-aminoaniline, was converted into a six-membered 2-phenylquinoxaline product through a reaction mechanism recently reported by Gopalaiah and co-workers for their similar CuBr-catalyzed protocol (Scheme 7, dashed arrows). ${ }^{20}$ In the presence of 0 -aminoaniline A, copper-catalyzed aerobic oxidation of 2-phenylethylamine would produce the crosscoupled imine B, which after copper-catalyzed benzylic oxidation, would lead to the formation of the keto-imine $\mathbf{E}$ via benzyl radical intermediate $\mathbf{C}$ and hydroperoxide $\mathbf{D}$.<smiles>NCCc1ccccc1</smiles><smiles>Nc1ccccc1/N=C/Cc1ccccc1</smiles>

$B$<smiles></smiles><smiles>Nc1ccccc1/N=C/Cc1ccccc1</smiles>

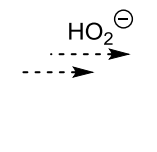<smiles>Nc1ccccc1/N=C/C(O)c1ccccc1</smiles>

Scheme 7 CuI-catalyzed formation of 2-phenylquinoxaline

Interestingly, the $\mathrm{CuBr}$-catalyzed oxidative coupling reaction of $o$-aminoanilines with 2-aryl/heteroarylethylamines described by Gopalaiah and co-workers was particularly efficient under 1 atm of molecular oxygen as the oxidant. Then, functionalized quinoxalines were isolated in high yields ranging from 78 to $97 \% .^{20}$ The reaction proceeded rapidly within 5-16h, in chlorobenzene, at room temperature, using 2aryl/heteroarylethylamines (1.2 equiv) and $o$-aminoanilines ( 1 equiv), in the presence of $\mathrm{CuBr}(10 \mathrm{~mol} \%)$ as the catalyst. Note that $\mathrm{CuBr}$ proved to be a more efficient catalyst than $\mathrm{CuBr}_{2}$ for this transformation. In the case of 2-phenylethylamine substrate, changing $\mathrm{CuBr}$ to $\mathrm{CuBr}_{2}$ led to a decreased yield in quinoxaline from 73 to $51 \%$, under the same reaction conditions. ${ }^{20}$

Note that different reaction pathways have been proposed for the copper-catalyzed formation of benzimidazoles (or quinoxalines) as shown in Scheme 8. Zhou and co-workers have envisioned the coordination of $\mathrm{Cu}^{\mathrm{II}}$ to benzylic amine followed by oxidation to generate the benzylimine intermediate, which reacts with $o$-aminoaniline giving the cross-coupled imine (path A). ${ }^{18}$ Gopalaiah and co-workers have similarly suggested direct transimination to form cross-coupled imine (path A) for their $\mathrm{CuBr} / \mathrm{O}_{2}$ system leading to quinoxalines, but they have also envisaged that 2-phenylethylimine may hydrolyze into phenylacetaldehyde, which, on further condensation with $o$ aminoaniline, forms the cross-coupled imine (path B). ${ }^{20} \mathrm{Xu}$ and co-workers have proposed an alternative route in which the CuI-catalyzed aerobic oxidation of amines under air produces the homocoupled imine intermediate, which then reacts with $o$ aminoaniline to give the cross-coupled imine through a transimination step (path C). ${ }^{19}$ Because of the presence of benzaldehyde as the by-product in reactions with low conversion, $\mathrm{Xu}$ and co-workers have also envisaged that benzylimine can hydrolyze into benzaldehyde and then affords the cross-coupled imine by condensation reaction (path B). The last steps of the process leading to the target benzimidazole heterocycle would involve intramolecular cyclization and subsequent oxidation as reported in reaction scheme 1 .

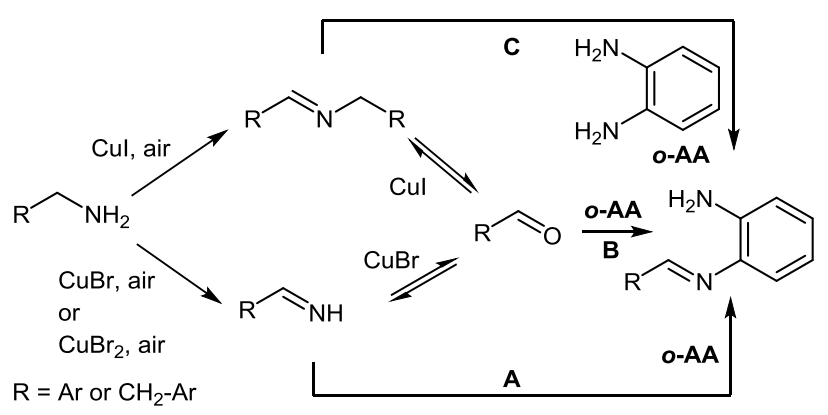

Scheme 8 Possible pathways for the copper-catalyzed aerobic cross-coupling of primary amines

In addition to copper systems, iron catalysts are also ideal candidates for such transformations, because iron shows variable valences and fulfills the requirements for green chemistry. Inspired by the iron-mediated catalytic system reported by $\mathrm{Xu}$ and co-workers for the preparation of imines through aerobic oxidative coupling of amines under air, ${ }^{21} \mathrm{Lu}$ and co-workers have demonstrated that the aerobic oxidative cyclocondensation of benzylic primary amines (1.2 equiv) and $o$-aminoaniline ( 1 equiv) can be achieved by the synergistic combination of $\mathrm{Fe}\left(\mathrm{NO}_{3}\right)_{3}$ (5 mol\%) and electron-deficient 2,2,6,6-tetramethyl-1-piperidyl-1-oxy radical (TEMPO) (5 mol\%), under solvent-free conditions, in open air. ${ }^{22}$ Variously substituted benzylic amines were converted into 2-substituted benzimidazoles in high yields (78-93\%), at $110^{\circ} \mathrm{C}$ for $24-28 \mathrm{~h}$. The first step of the proposed reaction mechanism consists of the aerobic Fe/TEMPO-catalyzed oxidation of benzylic amine to the corresponding benzylimine intermediate in a way reminiscent of that reported by $\mathrm{Hu}$ and Kerton for the aerobic $\mathrm{Cu} / \mathrm{TEMPO}$-catalyzed version (Scheme 9). ${ }^{23}$ The mechanism pursues following reaction scheme 8 (path A or B). 


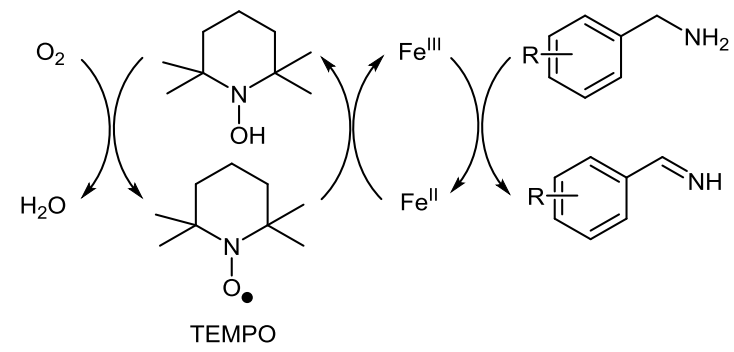

Scheme 9 Proposed mechanism for $\mathrm{Fe}\left(\mathrm{NO}_{3}\right)_{3} / \mathrm{TEMPO}$-catalyzed aerobic oxidation of benzylic amines to benzylimines

Recently, Gopalaiah and Chandrudu have described a significantly improved Fe-catalyzed protocol for the synthesis of 2-substituted benzimidazoles, without the need of adding TEMPO. ${ }^{24}$ Through optimization studies, they have compared the ability of $\mathrm{Fe}^{\mathrm{II}}$ and $\mathrm{Fe}^{\mathrm{III}}$ (10 mol\%) to catalyze the aerobic coupling of benzylamine (1.2 equiv) and $o$-aminonaniline (1 equiv), in chlorobenzene at $110^{\circ} \mathrm{C}$ for $18 \mathrm{~h}$ under air. They have found that $\mathrm{Fe}^{\mathrm{II}}$, especially $\mathrm{FeBr}_{2}$, is the best choice for the oxidative cyclocondensation reaction leading to 2 phenylbenzimidazole in $78 \%$ yield. Using $1 \mathrm{~atm}$ of molecular oxygen instead of air atmosphere, the iron catalyst loading could be reduced to $5 \mathrm{~mol} \%$, while the yield of benzimidazole product significantly increased to $92 \%$ within only $4 \mathrm{~h}$. A large molecular diversity could be attained through the variation of both benzylic amines and $o$-aminoanilines (Figure 5).

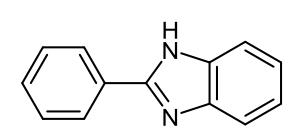

$92 \%$

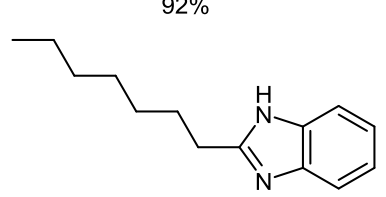

$73 \%$

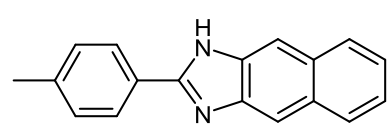

$76 \%$<smiles>c1ccc2[nH]c(-c3ccc4c(c3)OCO4)nc2c1</smiles>

$89 \%$<smiles>Cc1ccc(-c2nc3ccc(C)cc3[nH]2)cc1</smiles>

$82 \%$

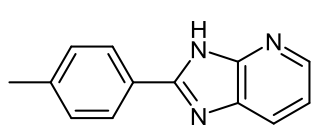

$80 \%$

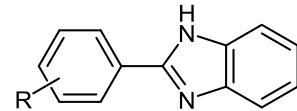

$\mathrm{R}=p-\mathrm{Me}, 93 \% ; \mathrm{R}=p-\mathrm{F}, 87 \%$ $\mathrm{R}=p-\mathrm{OMe}, 96 \% ; \mathrm{R}=0-\mathrm{OMe}$, $87 \% ; \mathrm{R}=\mathrm{o}-\mathrm{Cl}, 81 \%$<smiles>c1csc(-c2nc3ccccc3[nH]2)c1</smiles>

$81 \%$<smiles>c1ccc2[nH]c(-c3ccncc3)nc2c1</smiles>

$65 \%$

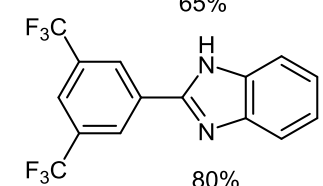<smiles>Cc1ccc(-c2nc3ccc([N+](=O)[O-])cc3[nH]2)cc1</smiles>

$79 \%$

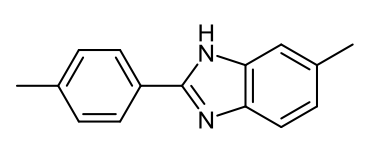

$82 \%$
Figure 5 Yields of representative 2-substituted benzimidazoles synthesized through $\mathrm{FeBr}_{2}$-mediated oxidative cross-coupling ${ }^{24}$
Interestingly, the non-activated primary amine $n$-octylamine was also a good substrate for this oxidative coupling reaction with $o$-aminoaniline, affording the corresponding benzimidazole in $73 \%$ yield. The proposed reaction mechanism was close to scheme 8 (path A or C) reported for the copper-mediated catalytic systems. Furthermore, the methodology could be applied to the synthesis of variously substituted benzothiazoles and benzoxazoles.

From the perspective of green chemistry and because metal residues may constitute a serious problem in the synthesis of pharmaceuticals and functional materials, chemists have shifted their attention to other eco-friendly protocols such as metal-free catalyzed reactions.

\subsection{Metal-free catalyzed reactions}

Alternative metal-free catalytic systems have been developed for the oxidative cross-coupling of primary amines including photocatalyzed and organocatalyzed reactions.

\section{Heterogeneous metal-free catalysis}

Owing to the natural abundance of carbon together with the need of minimizing the production of wastes and achieving optimal economic viability, the use of carbon catalysts has emerged in synthetic strategies. ${ }^{25}$ Especially, graphene oxide (GO), a water-soluble derivative of graphene, has been utilized for the (GO)-mediated oxidative coupling of primary amines to imines. ${ }^{26}$ However, most of the reactions require high weight loading of GO relative to the substrate, due to the moderate catalytic efficiency of GO when used as a substitute for metal catalysts. Loh and co-workers have reported a sequential base and acid treatment of GO that markedly improves its catalytic efficiency by generating porosity. Thanks to the utilization of porous graphene oxide $(p-\mathrm{GO}),{ }^{27}$ the oxidative cyclocondensation of benzylamine (1 equiv) and $o$ aminonaniline (1.5 equiv) could be performed, under air in acetonitrile, at $90{ }^{\circ} \mathrm{C}$, for $12 \mathrm{~h}$, affording 2-phenylbenzimidazole in $77 \%$ yield (Scheme 10). The extension of this protocol to other amine substrates has not been reported.

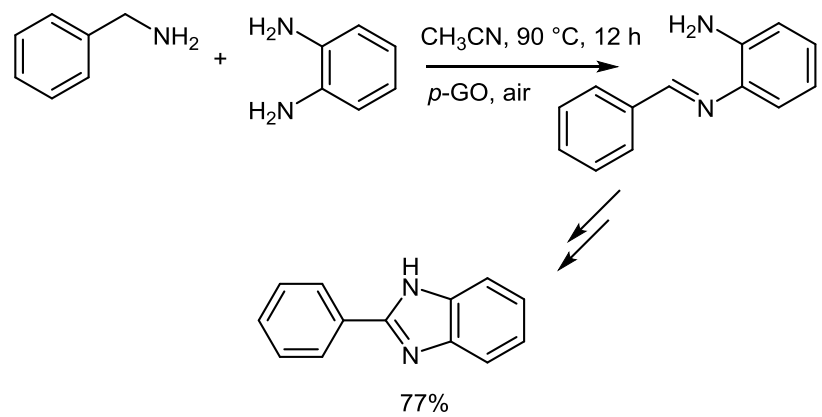

Scheme 10 One-pot aerobic $p$-GO catalyzed synthesis of 2phenylbenzimidazole. ${ }^{27}$ 
The utilization of sunlight as a non polluting energy source for chemical transformations has recently attracted much attention. ${ }^{28}$ Although several aerobic photocatalytic oxidation of primary amines to imines have been developed, ${ }^{29}$ a sole photocatalyzed oxidative cross-coupling reaction for the synthesis of benzimidazoles has been reported to the best of our knowledge. Blechert and co-workers have demonstrated that the utilization of mesoporous graphite carbon nitride (mpg$\mathrm{C}_{3} \mathrm{~N}_{4}$ ) photocatalyst, and visible light, allowed the complete conversion of benzylic amines to imines in acetonitrile at $80{ }^{\circ} \mathrm{C}$ but under high oxygen pressure $(0.5 \mathrm{MPa}) .{ }^{30}$ Interestingly, the mpg- $\mathrm{C}_{3} \mathrm{~N}_{4}$ photocatalyst could be easily separated and reused three times, without loss of catalytic activity. In the presence of $\mathrm{N}$-methyl-o-aminoanilines (3 equiv) (or mercaptoaniline), at $100^{\circ} \mathrm{C}$, the imines resulting from the oxidative coupling reaction could be engaged in situ, in an intramolecular cycloaddition reaction and subsequent oxidation to give 1,2-disubstituted benzimidazoles (or 2-substituted benzothiazoles) with high levels of conversion (91-99\%) within 4-6 h (Scheme 11).

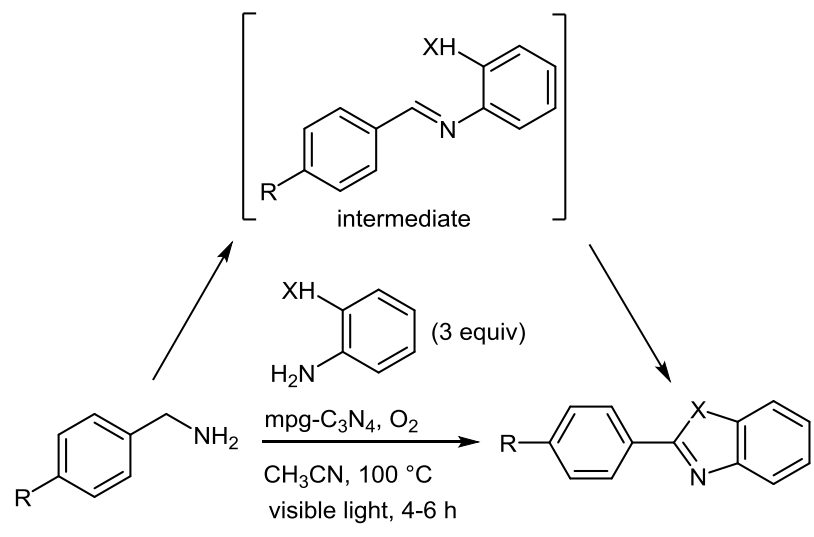

$\mathrm{R}=\mathrm{H}, \mathrm{Me}, \mathrm{OMe}, \mathrm{C}$

$$
\mathrm{X}=\mathrm{S}, \mathrm{NMe}
$$

Scheme 11 One-pot aerobic photocatalytic synthesis of benzimidazoles and benzothiazoles

\section{Homogeneous metal-free catalysis}

The use of small organic molecules to catalyse organic transformations, is a relatively popular field within the domain of organic synthesis. ${ }^{31}$ However, reports of the use of organocatalysts to mediate the aerobic oxidative cross-coupling of amines giving benzimidazoles products are rather scarce.

Ogawa and co-workers have shown that the oxidative crosscoupling of primary amines could be achieved efficiently using salicylic acid derivatives as organocatalysts. Optimization studies revealed that 4,6-dimethoxysalicylic acid (5 mol \%) was the most effective organocatalyst for the oxidative cyclocondensation reaction of benzylic amines (1.5 equiv) with $o$-aminoanilines ( 1 equiv), under an oxygen atmosphere ( 0.1 $\mathrm{MPa}$ ), in toluene at $110^{\circ} \mathrm{C}$ for $12 \mathrm{~h} .{ }^{32}$ Diverse substituents on the phenyl group of benzylamines or on the aromatic ring of $o$ aminoanilines were well tolerated, affording 2-substituted benzimidazole derivatives in high yields ranging from 85 to 95\% (Scheme 12). Through additional experiments, the authors have demonstrated that the oxidation of benzylamine proceeds following a radical mechanism.<smiles>[R]c1cccc2nc(-c3ccccc3)[nH]c12</smiles>

Scheme 12 One-pot aerobic organocatalyzed cascade reaction affording 2-substituted benzimidazole derivatives.

Except for few exceptions, 11,30 the different oxidative crosscoupling protocols presented until now describe the synthesis of 2-substituted benzimidazole derivatives. A last example of homogeneous metal-free catalysis is attractive because it gives also access to pharmaceutically relevant 1,2-disubstituted benzimidazoles. Recently, Bharate and co-workers have developed a metal-free method for the synthesis of 1,2disubstituted benzimidazoles from benzylamine substrates and $N$-phenyl-o-aminoaniline, using an imidazolium-based ionic liquid as the reaction medium, which can be recycled several times without significant loss of catalytic activity. ${ }^{33}$ The process involves the oxidative cyclocondensation reaction of the benzylamine substrate ( 2 equiv) with $N$-phenyl-o-aminonaniline (1 equiv), in 1-butyl-3-methylimidazolium tetrafluoroborate as the ionic liquid $(0.5 \mathrm{~mL})$, heated at $120{ }^{\circ} \mathrm{C}$ for $10 \mathrm{~h}$. Variously substituted benzylamines afforded the corresponding 1,2disubstituted benzimidazoles, in high yields (88-98\%), without particular electronic or steric effects of the substituents (Figure 6). Note that non-activated aliphatic amines failed to produce the corresponding benzimidazole derivatives under the same experimental conditions. This ionic-liquid-mediated process could be also applied to the synthesis of 2-phenyl-quinazolin-4$(3 \mathrm{H})$-one derivatives, in excellent yields ranging from 88 to $98 \%$, by changing $o$-aminoaniline to anthranilamide as the coupling partner (Scheme 13). Interestingly, it was observed that ionic liquid mediated all of the oxidation steps, whereas air did not play a role in the oxidation since the reaction could be performed under nitrogen or argon atmosphere.

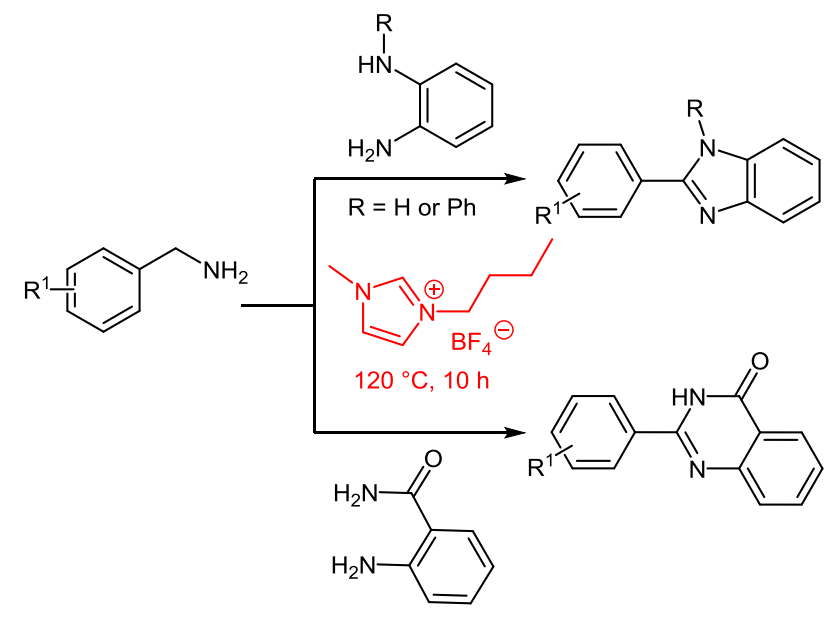

Scheme 13 Ionic-liquid mediated synthesis of benzimidazole and quinazolin-4-(3H)-one derivatives 


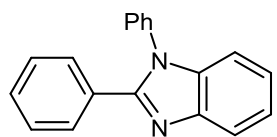

$98 \%$<smiles>Fc1ccc(-c2nc3ccccc3n2-c2ccccc2)cc1</smiles>

$95 \%$

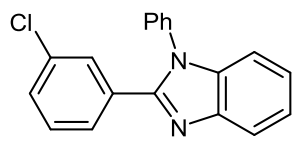

$88 \%$<smiles>c1ccc(-c2ccc(-c3nc4ccccc4n3-c3ccccc3)cc2)cc1</smiles>

$92 \%$<smiles>COc1ccc(-c2nc3ccccc3n2-c2ccccc2)cc1</smiles>

$95 \%$<smiles>Cc1ccc(-c2nc3ccccc3n2-c2ccccc2)cc1</smiles>

$91 \%$

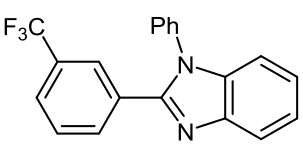

$93 \%$

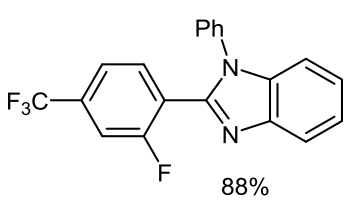

Figure 6 Yields of representative 1,2-disubstituted benzimidazoles synthesized through ionic liquid-mediated oxidative cross-coupling 33

At this stage, with only few exceptions, ${ }^{11,24}$ the major drawback of protocols based on the oxidative cross-coupling of amines is the difficulty of oxidizing non-activated primary amines. Accordingly, the molecular diversity is limited to derivatives bearing benzylic or allylic substituents at the 2 position of the benzimidazole framework. This compromises the overall efficiency of the reported works, because the well known coupling between an aldehyde and $o$-aminoaniline is more direct. Another weakness of these protocols is that the syntheses of 1,2-disubstituted benzimidazoles are rather scarce, $11,30,33$ while almost all pharmaceuticals are 1,2disubstituted derivatives. The discovery of biomimetic methods that utilize air as an environmentally benign oxidant, in a way reminiscent of enzyme catalysis, has proved to be effective to surpass these limitations.

\subsection{Bioinspired catalyzed reactions}

In 2012, Endo and Bäckvall have been the first to develop a biomimetic electron-transfer system for the rutheniumcatalyzed oxidative coupling of primary benzylic amines and $o$ hydroxyanilines to give 2-substituted benzoxazoles in high yields. ${ }^{34}$ Using 4-methylbenzylamine and $o$-aminoaniline as the amine substrates, they have been able to prepare the corresponding benzimidazole, though in $45 \%$ moderate yield (Scheme 14). The design of the system was inspired by the biological oxidation of alcohols. Instead of $\mathrm{NAD}^{+}$they have used a ruthenium complex as the substrate selective catalyst which dehydrogenates the benzylic amine to the corresponding benzylimine. The hydrogen atoms abstracted are transported to the electron-rich 2,6-dimethoxy-1,4-benzoquinone which serves as an electron-transfer mediator. The resulting hydroquinone is subsequently reoxidized by air with the assistance of an oxygen- activating cobalt complex. The molecular diversity accessible through this protocol has not been explored.
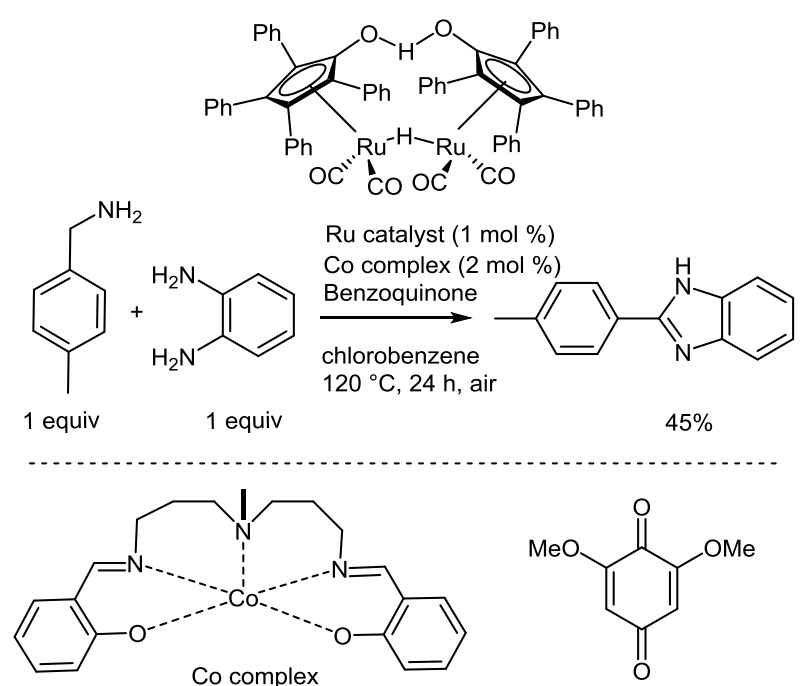<smiles>COC1=CC(=O)C=C(OC)C1=O</smiles>

$(20 \mathrm{~mol} \%)$

Scheme 14 Ru-catalyzed oxidative coupling to give benzimidazole by using a biomimetic oxidation system

A noticeable progress has arisen from the development of biomimetic quinone-based catalytic systems inspired by natural copper amine oxidases (CuAOs), a family of metalloenzymes which catalyzes the selective oxidation of primary amines to aldehydes, through the cooperation of a quinone-based cofactor, 2,4,5-trihydroxyphenylalanine quinone (TPQ), and a copper ion. $^{35}$ During the last five years, organic chemists have developed various bioinspired quinone-based catalytic systems for the aerobic oxidation of amines to imines under $1 \mathrm{~atm}$ of dioxygen or, more preferably, ambient air as the sole oxidant, with two objectives: (a) to achieve sustainable aerobic oxidation reactions and (b) to expand the scope of possible substrates. ${ }^{36}$

In this field, our group has recently described a bioinspired homogeneous catalytic system based on the cooperative action of a copper ion and a TPQ-like $o$-iminoquinone organocatalyst IMQ (Scheme 15), first discovered from electrochemical investigations. ${ }^{37}$ This protocol is reminiscent of other biomimetic catalytic systems, that uses transition metals as substrate-selective catalysts coupled with electron transfer mediators. ${ }^{38}$ Conversely, in our case, IMQ, which is generated in situ from the corresponding aminophenol AMQ, is the substrateselective catalyst while the copper ion serves as an electron transfer mediator. Low catalysts loadings are sufficient to oxidize benzylic, and non-activated aliphatic amines $\mathrm{RCH}_{2}-\mathrm{NH}_{2}$, to the homocoupled imine product at room temperature under ambient air. ${ }^{39}$ The oxidation process starts with atmospheric oxygen and continues in a cascade-like manner by passing the oxidation potential of oxygen through the copper salt to the organic mediator IMQ, which finally oxidizes the amine substrate. In the presence of a second primary amine R'- $\mathrm{NH}_{2}$, the generated homocoupled imine intermediate could be converted into a cross-coupled imine with complete selectivity. ${ }^{40}$ 
<smiles>CCCC1=CC(=O)C(O)=CC1=O</smiles><smiles>[R]C=N[Z]C(C)[C@@H](C)C[R]([Y6])[H]</smiles>

Scheme $15 \mathrm{Cu}(\mathrm{OAc})_{2} / \mathrm{IMQ}$-catalyzed aerobic oxidative crosscoupling of primary amines to imines

The mild reaction conditions being highly favorable for trapping the unstable alkylimines in situ for further reactions, we have utilized our bioinspired co-catalytic system, in a one pot cascade reaction sequence, leading to 1,2-disubstituted benzimidazoles. Optimization studies realized from the aerobic oxidative cross-coupling of benzylamine (1 equiv) with $\mathrm{N}$ phenyl-o-aminoaniline ( 1 equiv) indicated that higher yields were obtained by heating the coupling reaction mixture in methanol, at $45^{\circ} \mathrm{C}$ under air, in the presence of $6 \mathrm{~mol} \%$ of AMQ ( $4 \mathrm{~mol} \%$ followed by a $2 \mathrm{~mol} \%$ additional aliquot after $6 \mathrm{~h}$ ) and by using $\mathrm{CuBr}_{2}(0.4 \mathrm{~mol} \%)$ as the copper catalyst. ${ }^{41}$ The use of $\mathrm{CuBr}_{2}$ as the more efficient copper catalyst had also been observed by Zhou and co-workers. ${ }^{18} \mathrm{~A}$ large molecular diversity could be attained through the variation of both coupling partners leading to 1,2-disubstituted benzimidazole derivatives in good yields. It is important to note that, with the exception of $\beta$-branched alkylamines, non-activated primary aliphatic amines were found to be good coupling partners for the $\mathrm{CuBr}_{2} / \mathrm{IMQ}$ mediated aerobic oxidative cyclocondensation reaction with $\mathrm{N}$ substituted-o-aminoanilines provided a slightly elevated temperature of $60^{\circ} \mathrm{C}$ was used (Figure 7). ${ }^{41,42}$

Although $\mathrm{MeOH}$ proved to be the best solvent for the coupling reaction because it provides the ideal balance of IMQ solvation and reaction rate, when reactive $\mathrm{N}$-alkyl-o-aminoaniline were used as in situ imine traps, a concomitant formation of $\mathrm{N}$ alkylbenzimidazole by-product was observed, originating from the involvement of $\mathrm{MeOH}$ itself which acted as a carbon source. In these cases, the exclusive formation of 1,2-disubstituted benzimidazoles can be achieved in 2-propanol in the presence of water $(10 \%)$, which markedly accelerates the cyclization rate to the benzimidazoline intermediate. ${ }^{42}$ Accordingly, Barta and coworkers had previously reported a protocol for the preparation of benzimidazoles from a range of $o$-aminoanilines by simply heating these starting materials in supercritical $\mathrm{MeOH}$, which acts both as a solvent and carbon source, in the presence of copper-doped porous metal oxides. ${ }^{43}$<smiles>c1ccc(-c2nc3ccccc3n2-c2ccccc2)cc1</smiles>

$82 \%$<smiles>CC(C)(C)[14CH3]</smiles>

$75 \%$<smiles>c1ccc(-n2c(-c3ccc4ccccc4c3)nc3ccccc32)cc1</smiles>

$71 \%$<smiles>c1ccc(-n2c(-c3cccs3)nc3ccccc32)cc1</smiles><smiles>c1ccc(-n2c(C3CC3)nc3ccccc32)cc1</smiles>

$68 \%$<smiles>[R]c1ccc(-c2nc3ccccc3n2-c2ccccc2)cc1</smiles>

$\mathrm{R}=\mathrm{OMe}, 80 \% ; \mathrm{R}=\mathrm{F}, 80 \%$; $\mathrm{R}=\mathrm{CF}_{3}, 74 \% ; \mathrm{R}=\mathrm{NH}_{2}, 75 \%$; $\mathrm{R}=\mathrm{Bu}, 78 \% ; \mathrm{R}=\mathrm{Me}, 80 \%$<smiles>c1ccc(-n2c(-c3ccco3)nc3ccccc32)cc1</smiles><smiles>c1ccc(-n2c(C3CCCCC3)nc3ccccc32)cc1</smiles>

$58 \%$<smiles>Cn1c(C2CC2)nc2ccccc21</smiles>

$73 \%$<smiles>CCCCCCC/C(=C\C(=O)c1ccccc1)c1ccccc1</smiles>

$77 \%$<smiles>CC(C)Cc1nc2ccccc2n1C</smiles>

$62 \%$<smiles>c1ccc(Cn2c(C3CC3)nc3ccccc32)cc1</smiles>

$68 \%$

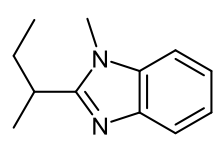

$42 \%$<smiles>CCCCCc1nc2ccccc2n1C</smiles>

$60 \%$<smiles>CCC(C)c1nc2ccccc2n1-c1ccccc1</smiles>

$51 \%$

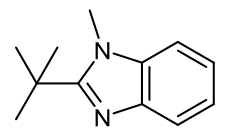

$38 \%$

Figure $\quad 7$ Yields of representative 1,2-disubstituted benzimidazoles synthesized through $\mathrm{CuBr}_{2} / \mathrm{IMQ}$-mediated oxidative cross-coupling

The reaction mechanism for the $\mathrm{CuBr}_{2}$ /IMQ-mediated aerobic cross-coupling reaction involves the oxidation of the primary amine $\mathrm{R}^{2} \mathrm{CH}_{2} \mathrm{NH}_{2}$ to the homocoupled imine intermediate through a transamination mechanism analogue to that reported for natural CuAOs (Scheme 16). In the presence of $o$ aminoaniline, the homocoupled imine intermediate is converted into cross-coupled imines through dynamic transimination. As a consequence, just one equivalent of each primary amine was sufficient to achieve exclusive formation of the cross-coupled imine product. Subsequent intramolecular cyclization to benzimidazoline and oxidation reactions as reported in reaction scheme 1 afford the 1,2-disubstituted benzimidazole derivatives with high atom economy. Note variously substituted 2benzimidazole derivatives could also be prepared using diverse $o$-aminoanilines. 42 


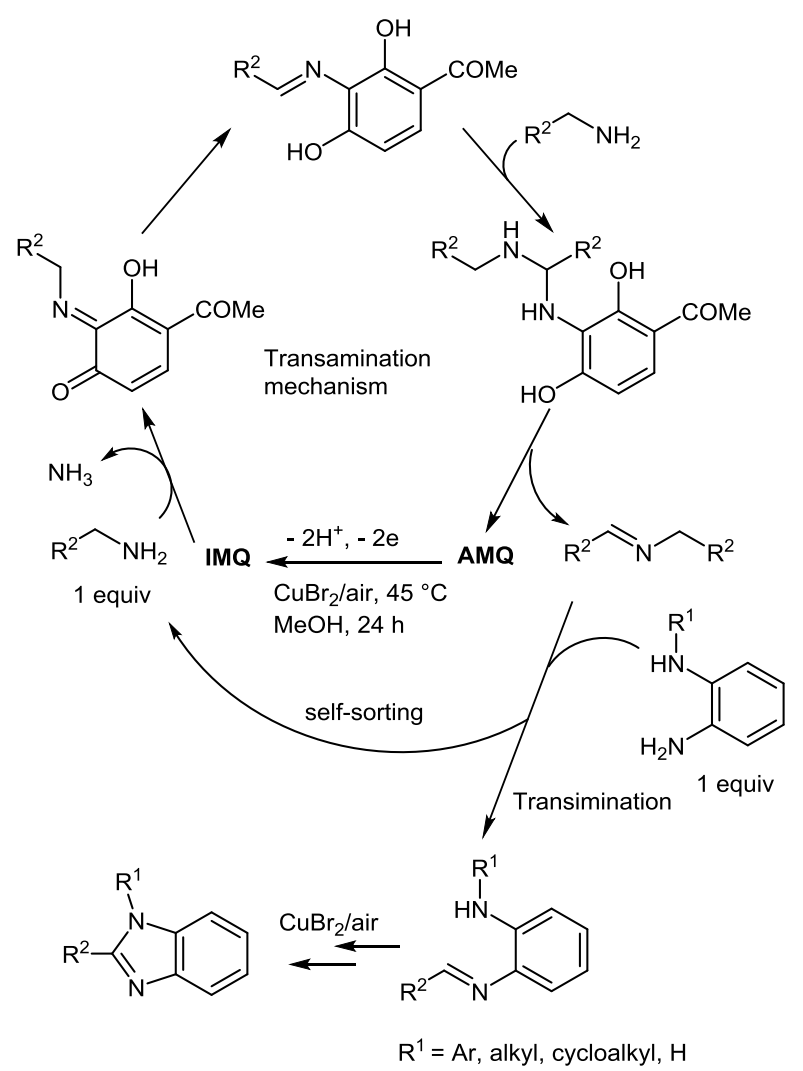

Scheme 16 Bioinspired $\mathrm{CuBr}_{2} / \mathrm{IMQ}$-mediated cascade reaction sequence affording 1,2-disubstituted benzimidazoles

Because the oxidation of the primary amine substrates by CuAOs is mediated by TPQ without involvement of the copper ion, ${ }^{44}$ we have envisioned significant modifications of our initial protocol to develop procedures, avoiding contamination of the final products by metal residues. Accordingly, the use of a commercially available starting material rather than AMQ, the precursor of IMQ, whose the synthesis requires two steps from 2-nitroresorcinol,37e would offer enhanced practicality while limiting the production of wastes. This is the reason why we have been drawn to the structure of natural purpurogallin (2,3,4,6-tetrahydroxy-5 $H$-benzocyclohepten-5-one) as a potential precursor of a highly reactive $o$-quinone-based organocatalyst. However, its limited availability led us to concentrate on its biosynthesis, which involves the oxidative dimerization of pyrogallol generated from gallic acid. ${ }^{45}$ Based on this insight, we have developed a double biomimetic reaction pathway resulting in the formation of 1,2-disubstituted

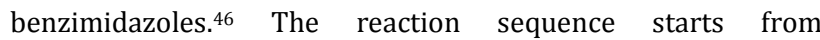
inexpensive commercially available pyrogallol and allows, under ambient air, the in situ generation of not easily accessible natural purpurogallin, which is further engaged in the transamination process analogue to that reported in reaction scheme 16, for producing, under single turnover, the active biomimetic organocatalyst IMQ' (Scheme 17). Dynamic transimination followed by intramolecular cyclization and subsequent oxidation reactions produced the 1,2-disubstituted benzimidazole derivatives.

\section{Purpurogallin biosynthesis mimicry}<smiles>C=CCCc1ccc(O)c(O)c1CO</smiles>

$(10 \mathrm{~mol} \%)$

Purpurogallin (5 mol\%)

CuAOs activity mimicry

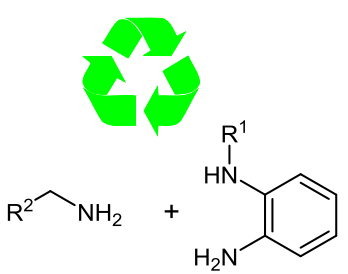<smiles>N=C1C(=O)C=c2cccc(O)c(=O)c2=C1O</smiles><smiles>[R]c1nc2ccccc2n1[R]</smiles>

Scheme 17 Bioinspired IMQ'-mediated cascade reaction sequence affording 1,2-disubstituted benzimidazoles

Because the synthesis of aliphatic imines is challenging due to their instability and isomerization into the enamine tautomer, which decomposes under ambient air, we have focused on the aerobic oxidative cyclocondensation of non-activated aliphatic amines and $\mathrm{N}$-methyl-o-aminoaniline. By mixing these amines substrates in the ratio $1: 1$, in the presence of $10 \mathrm{~mol} \%$ pyrogallol, thus generating $5 \mathrm{~mol} \%$ of IMQ', good yields of 1,2disubstituted benzimidazoles were obtained at $60^{\circ} \mathrm{C}$ within $60 \mathrm{~h}$ (Figure 8). Note this reaction had proved to be unsuccessful in the absence of $\mathrm{Cu}^{\mathrm{II}}$ cooperative catalyst when IMQ was used as the sole organocatalyst. ${ }^{42}$

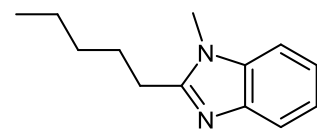

$67 \%$

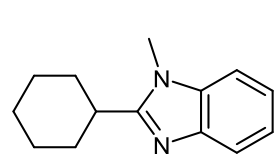

$64 \%$

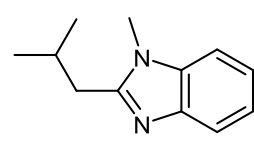

$74 \%$

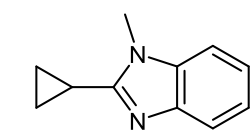

$76 \%$

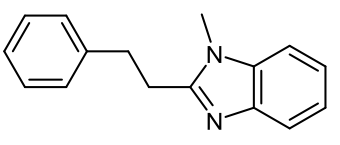

$63 \%$

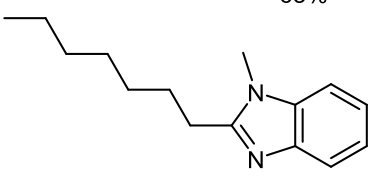

$62 \%$

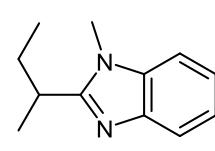

$52 \%$

Figure 8 Yields of representative 1,2-disubstituted benzimidazoles synthesized through IMQ'-mediated oxidative cyclocondensation reaction 


\section{Conclusion}

The oxidative cross-coupling of primary amines has received much attention over the last five years because it provides a straightforward protocol to synthesize substituted benzimidazole derivatives, through the variation of both commercially available cyclocondensation partners. Different methods have been presented including catalyst-free reactions together with catalyzed processes which encompasse metalcatalyzed, organocatalyzed, photocatalyzed and bioinspired catalyzed reaction types. Each method possesses its strengths and weaknesses.

Obviously, catalyst-free systems are very simple but still suffer from the requirement of stoichiometric or excess amounts of specific oxidants and/or high reaction temperatures.

The attention on highly abundant first-row transition metals such as copper or iron was raised to develop efficient metalcatalyzed methods but the presence of metal residues may constitute a serious problem in the synthesis of drugs and functional materials.

Alternative metal-free catalytic systems have been developed to avoid metal residues contamination. However, organocatalysis still requires high catalyst loadings while photocatalyzed reactions remain scarce despite the increasing interest for visible-light photocatalysis.

Bioinspired catalytic protocols have begun to emerge in synthetic strategies because of the capacity of natural $\mathrm{CuAOs}$ to perform controlled aerobic oxidation of amines under mild reaction conditions. The large molecular diversity accessible is interesting but the reaction times are still long.

Due to the prevalence of the benzimidazole framework in pharmaceuticals, the next few years will certainly see the advent of new protocols that will surpass the drawbacks of each method while increasing the scope and efficiency.

\section{References}

(1) New address: K. M. H. Nguyen, Institut de Biologie Intégrative de la Cellule, UMR 9198 CEA, CNRS, Université Paris Sud, 91191 CEA-Saclay, Gif-sur-Yvette (France)

(2) (a) Gaba, M.; Singh, S.; Mohan, C. Eur. J. Med. Chem. 2014, 76, 494 (b) Yadav, G.; Ganguly, S. Eur. J. Med. Chem. 2015, 97, 419.

(3) Vitaku, E.; Smith, D. T.; Njardarson, J. T. J. Med. Chem. 2014, 57, 10257.

(4) For a review, see: Preston, P. N. Chem. Rev. 1974, 74, 279.

(5) (a) Preston, P. N. Benzimidazoles, in The Chemistry of Heterocyclic Compounds, Weissenberger, A. and Taylor, E. C. Eds.; Wiley: New York, 1981, 1. (b) Banerjee, M.; Chatterjee, A.; Kumar, V.; Bhutia, Z. T.; Khandare, D. G.; Majik, M. S.; Roy, B. G. $R S C A d v .2014,4$, 39606.

(6) For selected examples, see: (a) Curini, M.; Epifano, F.; Montanari, F.; Rosati, O.; Taccone, S. Synlett. 2004, 10, 1832. (b) Chen, Y. -X.; Qian, L.-F.; Zhang, W.; Han, B. Angew. Chem. Int. Ed. 2008, 47, 9330. (c) Samanta, S.; Das, S.; Biswas, P. J. Org. Chem. 2013, 78, 11184. (d) Bai, G.; Lan, X.; Liu, X.; Liu, C.; Shi, L.; Chen, Q.; Chen, G. Green Chem. 2014, 16, 3160. (e) Sharma, H.; Singh, N.; Jang, D. O. Green Chem. 2014, 16, 4922. (f) Nagasawa, Y.; Matsusaki, Y.; Hotta, T.; Nobuta, T.; Tada, N.; Miura, T.; Itoh, A. Tetrahedron Lett 2014, 55, 6543. (g) Ghosh, P.; Subba, R. Tetrahedron Lett. 2015, 2691-2694. (h) Lee, Y.-S.; Cho, Y.-H., Lee, S. J.; Bin, J.-K.; Yang, J. H.; Chae, G. S.; Cheon, C.-H. Tetrahedron 2015, 71, 532. (i) Cimarelli,
C.; Di Nicola, M.; Diomedi, S.; Giovannini, R.; Hamprecht, D.; Properzi, R.; Sorana, F.; Marcantoni, E. Org. Biomol. Chem. 2015, 13, 11687. (j) Lee, Y.-S.; Cheon, C.-H. Adv. Syn. Catal. 2015, 357, 2951. (k) Katla, R. ; Chowrasia, R.; Manjari, P. S.; Domingues, N. L. C. $R S C A d v .2015,5$, 41714. (l) Pramanik, N. Sarkar, S. ; Roy, D.; Debnath, S.; Ghosh, S.; Khamarui, S.; Maiti, D. K. RSC Adv. 2015, 5 101959. (m) Wade, A. R.; Pawar, H. R.; Biware, M. V.; Chikate, R. C. Green Chem. 2015, 17, 3879. (n) Bala, M.; Kumar Verma, P.; Sharma, D.; Kumar, N.; Singh, B. Mol. Div. 2015, 19, 263. (o) Tian, X.; Song, L.; Li, E.; Wang, Q.; Yu, W.; Chang, J. RSC Adv. 2015, 5, 62194. (p) Mahesh, D.; Sadhu, P.; Punniyamurthy, T. J. Org. Chem. 2016, 81, 3227. (q) Azizian, J.; Torabi, P. ; Noei, J. Tetrahedron Lett. 2016, 57, 185. (r) Smitha, G. ; Sreekumar, K. . RSC Adv. 2016, 6, 18141. (s) Rojas-Buzo, S.; Garcia-Garcia, P.; Corma, A. ChemCatChem, 2017, 9, 997. (t) Martins, G. M.; Puccinelli, T.; Gariani, R.A. ; Xavier, F. R.; Silveira, C. C. ; Mendes, S. R. Tetrahedron Lett. 2017, 58, 1969.

(7) For recent examples, see: (a) Chebolu, R.; Kommi, D. N.; Kumar, D.; Bollineni, N.; Chakraborti, A. K. J. Org. Chem. 2012, 77, 10158. (b) Kumar, T. B. ; Sumanth Ch.; Dhanunjaya Rao, A. V.; Kalita, D.; Srinivasa Rao, M.; Chandra Sekhar, K. B.; Shiva Kumar, K.; Pal, M. RSC Adv. 2012, 2, 11510. (c) Kumar, D.; Kommi, D. N.; Chebolu, R.; Garg. S. K.; Kumar, R.; Chakraborti, A. K. RSC Adv. 2013, 3, 91. (d) Maleki, A.; Ghamani, N.; Kamalzare, M. RSC Adv. 2014, 4, 9416. (e) Majumdar, S.; Chakraborty, M.; Pramanik, N.; Maiti, D. K. RSC Adv. 2015, 5, 51012. (f) Sharma, H.; Kaur, N.; Singh, N.; Jang, D. O. Green Chem. 2015, 17, 4263. (g) Hu, Z.; Zhao, T.; Wang, M.; Wu, J.; Yu, W.; Chang, J. J. Org. Chem. 2017, 82, 3152.

(8) For a recent review, see: (a) Carvalho, L. C. R., Fernandes, E.; Marques, M. M. B. Chem. Eur. J. 2011, 17, 12544 and references cited therein. For selected recent examples, see: (b) Pizzeti, M.; De Luca, E.; Petricci, E.; Porcheddu, A.; Taddei, M. Adv. Synth. Catal. 2012, 354, 2453. (c) Jui, N. T.; Buchwald, S. L. Angew. Chem. Int. Ed. 2013, 52, 11624. (d) Kommi, D. ; Jadhavar, P.D. ; Kumar, D. ; Chakraborti, A. K. ; Green Chem. 2013, 15, 798. (e) Tran, L. Q.; Li, J.; Neuville, L. J. Org. Chem. 2015, 80, 6102. (f) Xia, Y.; Lin, L.; Chang, F.; Liao, Y.; Liu, X.; Feng, X. Angew. Chem. Int. Ed. 2016, 55, 12228. (g) Hu, B.; Dong, W.; Feng, Z.; Gao, X.; Gao, H.; Xie, X.; Zhang, Z. Asian J. Org. Chem. 2016, 5, 1467. (h) Zurita, D. A.; Flores-Alamo, M.; Garcia, J. J. Dalton Trans. 2016, 45, 10389. (i) Xia, j;. Yang, X.; Li, Y.; Li, X. Org. Lett. 2017, 19, 3243. (j) Xie, C.; Han, X.; Gong, J.; Li, D.; Ma, C. Org. Biomol. Chem. 2017, 15, 5811.

(9) For selected recent examples, see: (a) Zheng, N.; Anderson, K. W.; Huang, X.; Nguyen, H. N.; Buchwald, S. L. Angew. Chem. Int. Ed. 2007, 46, 7509. (b) Zou, B.; Yuan, Q.; Ma, D. Angew. Chem. Int. Ed. 2007, 46, 2598. (c) Brasche, G.; Buchwald, S. L.; Angew. Chem. Int. Ed. 2008, 47, 1932. (d) Saha, P.; Ramana, T.; Purkait, N.; Ashif Ali, Md; Paul, R.; Punniyamurthy, T. J. Org. Chem. 2009, 74, 8719. (e) Hirano, K.; Biju, A. T.; Glorius, F. J. Org. Chem. 2009, 74, 9570. (f) Saha, P.; Ashif Ali, Md; Ghosh, P.; Punniyamurthy, T.; Org. Biomol. Chem. 2010, 8, 5692. (g) Zhao, D.; Hu, J.; Wu, N. ; Huang, X.; Qin, X.; Lan, J.; You, J.; Org. Lett. 2011, 13, 6516. (h) Li, J.; Bénard, S.; Neuville, L.; Zhu, J. Org. Lett. 2012, 14, 5980. (i) Kumar Alla, S.; Kiran Kumar, R.; Sadhu, P.; Punniyamurthy, T. Org. Lett. 2013, 15, 1334. (j) Baars, H.; Beyer, A.; Kohlhepp, S. V.; Bolm, C. Org. Lett. 2014, 16, 536. (k) Lin, J.-P.; Zhang, F.-H.; Long, Y.-Q. Org. Lett. 2014, 16, 2822. (l) Sun, M. ; Chen, C. ; Bao, W. RSC Adv. 2014, 4, 47373. (m) Li, J. ; Gu, H. ; Wu, C. ; Du, L. Dalton Trans. 2014, 43, 16769.

(10) For selected recent examples, see: (a) Blacker, A. J.; Farah, M. M.; Hall, M. I.; Marsden, S. P.; Saidi, O.; Williams, J. M. J. Org. Lett. 2009, 11, 2039. (b) Moorthy, J. N.; Neogi, I. Tetrahedron Lett. 2011, 52, 3868. (c) Lan, Y. -S.; Liao, B. -S.; Liu, Y. -H.; Peng, S. -M.; Liu, S. -T. Eur. J. Org. Chem. 2013, 23, 5160. (d) Yu, J.; Xu, J.; Lu, M. Appl. Organomet. Chem. 2013, 27, 606. (e) Wang, H.; Zhang, J.; Cui, Y. M.; Yang, K. -F. ; Zheng, Z. -J. ; Xu, L. -W. RSC Adv. 2014, 4, 34681. (f) Ramachandran, R.; Prakash, G.; Selvamurugan, S.; Viswanathamurthi, P.; Malecki, J. G.; Ramkumar, V. Dalton Trans. 2014, 43, 7889. (g) Reddy Marri, M.; Peraka, S.; Kumar Macharla, 
A.; Mameda, N.; Kodumuri, S.; Nama, N. Tetrahedron Lett. 2014, 55, 6520. (h) Wang, Z. -G.; Xia, Y. -G.; Jin, Y.; Lu, M. Appl. Organomet. Chem. 2015, 29, 109. (i) Shi, X.; Guo, J.; Liu, J.; Ye, M.; Xu, Q. Chem. Eur. J. 2015, 21, 9988. (j) Lai, Y. -L.; Ye, J. -S.; Huang, J. -M. Chem. Eur. J. 2016, 22, 5425.

(11) Nguyen, T. B.; Ermolenko, L.; Dean, W. A.; Al-Mourabit, A. Org. Lett. 2012, 14, 5948.

(12) Nguyen, T. B.; Ermolenko, L.; Al-Mourabit, A. Green Chem. 2013, 15, 2713.

(13) Yu, J.; Lu, M. Synth. Commun. 2014, 44, 2520.

(14) Tangella, Y.; Lakshmi Manasa, K.; Sathish, M.; Alarifi, A.; Kamal, A. ChemistrySelect, 2016, 1, 2895.

(15) Naresh, G.; Kant, R.; Narender, T. J. Org. Chem. 2014, 79, 3821

(16) For recent reviews, see: (a) Wendlandt, A. E.; Suess, A. M.; Stahl, S. S. Angew. Chem. Int. Ed. 2011, 50, 11062. (b) Allen, S. E.; Walvoord, R. R.; Padilla-Salinas, R.; Kozlowski, M. C. Chem. Rev. 2013, 113, 6234. (c) Guo, X. -X.; Gu, D. -W.; Wu, Z.; Zhang, W. Chem. Rev. 2015, 115, 1622. (d) Subramanian, P.; Rudolf, G. C.; Kaliappan, K. P. Chem. Asian. J. 2016, 11, 168. (e) Fürstner, A. ACS Central Sci. 2016, 2, 778. (f) Shang, R.; Ilies, L.; Nakamura, E. Chem. Rev. 2017, 117, 9086.

(17) (a) Patil, R. D.; Adimurthy, S. Adv. Synth. Catal. 2011, 353, 1695. (b) Patil, R. D.; Adimurthy, S. RSC Adv. 2012, 2, 5119.

(18) Xiao, T.; Xiong, S.; Xie, Y.; Dong, X.; Zhou, L. RSC Adv. 2013, 3, 15592.

(19) Liu, J.; Wang, C.; Ma, X.; Shi, X. ; Wang, X.; Li, H.; Xu, Q. Catal. Lett. 2016, 146, 2139.

(20) Gopalaiah, K.; Saini, A.; Chandrudu, S. N. ; Rao, D. C. ; Yadav, H. ; Kumar, B. Org. Biomol. Chem. 2017, 15, 2259.

(21) Zhang, E.; Tian, H.; Xu, S.; Yu, X.; Xu, Q. Org. Lett. 2013, 11, 2704.

(22) Yu, J.; Xia, Y.; Lu, M. Synth. Commun. 2014, 44, 3019.

(23) Hu, Z.; Kerton, F. M. Org. Biomol. Chem. 2012, 10, 1618.

(24) Gopalaiah, K.; Chandrudu, S. N. RSC Adv. 2015, 5, 5015.

(25) For a review, see: Su, C.; Loh, K. P. Acc. Chem. Res. 2013, 46, 2275.

(26) (a) Huang, H.; Huang, J.; Liu, Y. -M. Liu, He, H. -Y.; Cao, Y.; Fan, K. N. Green Chem. 2012, 14, 930. (b) Su, C.; Acik, M.; Takai, K.; Lu, J.; Hao, S. -J. ; Zheng, Y.; Wu, P.; Bao, Q.; Enoki, T.; Chabal, Y. J.; Loh, K. P. Nat. Commun. 2012, 3, 1298.

(27) Su, C.; Tandiana, R.; Balapanuru, J.; Tang, W.; Pareek, K. ; Nai, C. T.; Hayashi, T. ; Loh, K. P. J. Am. Chem. Soc. 2015, 137, 685.

(28) For recent reviews, see: (a) Lang, X.; Chen, X.; Zhao, J. Chem. Soc. Rev. 2014, 43, 473. (b) Lang, X.; Ma, W.; Chen, C.; Ji, H.; Zhao, J. Acc. Chem. Res. 2014, 47, 355.

(29) For a recent review, see: Chen, B.; Wang, L.; Gao, S. ACS Catal. 2015, 5, 5851 and references therein. See also: (c) Ushakov, D. B.; Plutschack, M. B.; Gilmore, K.; Seeberger, P. H.; Chem. Eur. J. 2015, 21, 6528. (d) Raza, F.; Park, J. H.; Lee, H. -R.; Kim, H. I.; Jeon, S. -J. ; Kim, J. -H. ACS Catal. 2016, 6, 2754.

(30) Su, F.; Mathew, S. C. ; Möhlmann, L. ; Antonietti, M. ; Wang, X.; Blechert, S. Angew. Chem. Int. Ed. 2011, 50, 657.
(31) For selected reviews, see: (a) MacMillan, D. W. C. Nature, 2008, 455, 304. (b) Holland, M. C.; Gilmour, R. Angew. Chem. Int. Ed. 2015, 54, 3862.

(32) Dong, C. -P.; Higashiura, Y.; Marui, K.; Kumazawa, S.; Nomoto, A.; Ueshima, M.; Ogawa, A. ACS Omega, 2016, 1, 799.

(33) Sharma, R.; Abdullaha, M.; Bharate, S. B. Asian J. Org. Chem. 2017, DOI:10.1002/ajoc.201700214.

(34) Endo, Y.; Bäckvall, J. -E. Chem. Eur. J. 2012, 18, 13609.

(35) Janes, S. M.; Mu, D.; Wemmer, D. ; Smith, A. J.; Kaur, S.; Malty, D.; Burlingame, A. L.; Klinman, J. P. Science, 1990, 248, 981.

(36) For recent reviews or perspectives, see: (a) Largeron, M.; Fleury, M. -B. Science, 2013, 339, 43. (b) Wendlandt, A. E.; Stahl, S. S. Angew. Chem. Int. Ed. 2015, 54, 14638. (c) Largeron, M. Org. Biomol. Chem. 2017, 15, 4722 and references therein.

(37) For leading references about our electrochemical investigations, see: (a) Largeron, M.; Fleury, M. -B. J. Org. Chem. 2000, 65, 8874. (b) Largeron, M.; Neudörffer, A.; Vuilhorgne, M.; Blattes, E.; Fleury, M. -B. Angew. Chem. Int. Ed. 2002, 41, 824. (c) Largeron, M.; Neudörffer, A.; Fleury, M. -B. Angew. Chem. Int. Ed. 2003, 42, 1026. (d) Blattes, E.; Fleury, M. -B.; Largeron, M. J. Org. Chem. 2004, 69, 882. (e) Xu, D.; Chiaroni, A.; Fleury, M. -B.; Largeron, M. J. Org. Chem. 2006, 71, 6374. (f) Largeron, M.; Chiaroni, A.; Fleury, M. -B. Chem. Eur. J. 2008, 14, 996. (g) Largeron, M. Fleury, M. -B. Org. Lett. 2009, 11, 883. (h) Largeron, M.; Fleury, M. -B.; Strolin Benedetti, M. Org. Biomol. Chem. 2010, 8, 3706.

(38) Piera, J.; Bäckvall, J. -E. Angew. Chem. Int. Ed. 2008, 47, 3506.

(39) Largeron, M.; Fleury, M. -B. Angew. Chem. Int. Ed. 2012, 51, 5409.

(40) Largeron, M.; Fleury, M. -B. Chem. Eur. J. 2015, 21, 3815.

(41) Nguyen, K. M. H.; Largeron, M. Chem. Eur. J. 2015, 21, 12606.

(42) Nguyen, K. M. H.; Largeron, M. Eur. J. Org. Chem. 2016, 1025.

(43) Sun, Z. ; Bottari, G. Barta, K. Green Chem. 2015, 17, 5172.

(44) For a recent review, see: Klinman, J. P.; Bonnot, F. Chem. Rev. 2014, 114, 4343 .

(45) (a) Dürckeimer, W.; Paulus, E. F. Angew. Chem. Int. Ed. 1985, 24, 224. (b) Ellerbrock, P.; Armanino, M. K.; Ilg, R.; Webster, R.; Trauner, D. Nat. Chem. 2015, 7, 879.

(46) Largeron, M.; Fleury, M. -B. Chem. Eur. J. 2017, 23, 6763. 


\section{Biosketches}

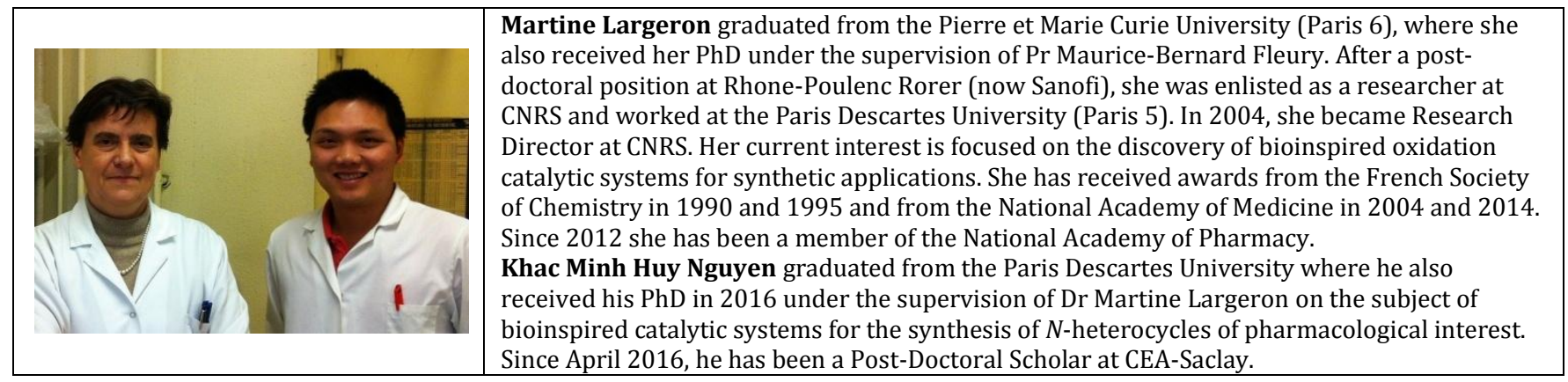

For Reviews, include photos and short biographical text for all authors. If the photo is of a group of people, specify who is shown where.

For Short Reviews, restrict the photo and biographical text to the main (starred) author(s). If the photo displays coworkers, however, they can be mentioned briefly within the main author's short biography.

Photographs (.jpg or .tif format) must be a minimum of $300 \mathrm{dpi}$ in order to reproduce well in print. 